\title{
6 Ruins on the Beach
}

\section{Old Sites}

Images of Kenya's coastal regions are usually images of idyllic beaches. Endless stretches of white coral sand, turquoise blue water and shady coconut trees. No people. These images always seem to accompany promises of exclusiveness and access to otherwise closed territories - premium lounges, upgraded suites, sea view cottages. They emerge from ads and portable media, smartphones on the train during a tedious ride through grey suburbs. Language turned into slogans, spaces to fill an online form, flights quickly booked. A trip to Kenya, deserved and achieved.

While a few premium resorts around Diani affirm phantasies of deserted beaches as spaces of prestige and elitism, most other hotels and beach clubs do not. Already before the Covid-19 pandemic, they have been closed down in the course of a giant crisis in tourism, economy and politics, and have begun to fall into ruins. Outside the premium littoral, this creates fears of danger. It is not only the guidebooks that provide orientation in this space that no longer seems to offer any surprises, but also the many signboards that are posted everywhere, that ask us to beware - of the young men, of falling coconuts and rubble, of polluted water and venereal disease.

At the beach, ruins look astonishingly similar. As if the architecture of the non-place was so uniform and so reduced to just one effect - providing space and opportunities to tourists for their consumption - that the decaying matter left behind had no chance to turn into anything at all. Just rectangular shapes and circular shapes and blocked entries. Blocked exits. Empty pools that get filled again: with rain, rodents that have fallen into the rain water and insects that feed on the dead rodents. Broken windows with mummified frangipani blossoms and dusty cobwebs. Musty mattresses on filthy bedsteads. The only traces of human life spent and lived seem to be faeces that reek in the sun.

Some of the ruins exhibit ruined animals (Figures 6.1-6.6). Giraffes that peel from the walls of an old casino, an elephant on a door, a buffalo on a car park. Hollow eyes, greyish coats, missing legs. Ears gone by. These animals have always been dead, and it is only now, surprisingly, as everything falls into ruins, that they come alive. Like their cousins in the 


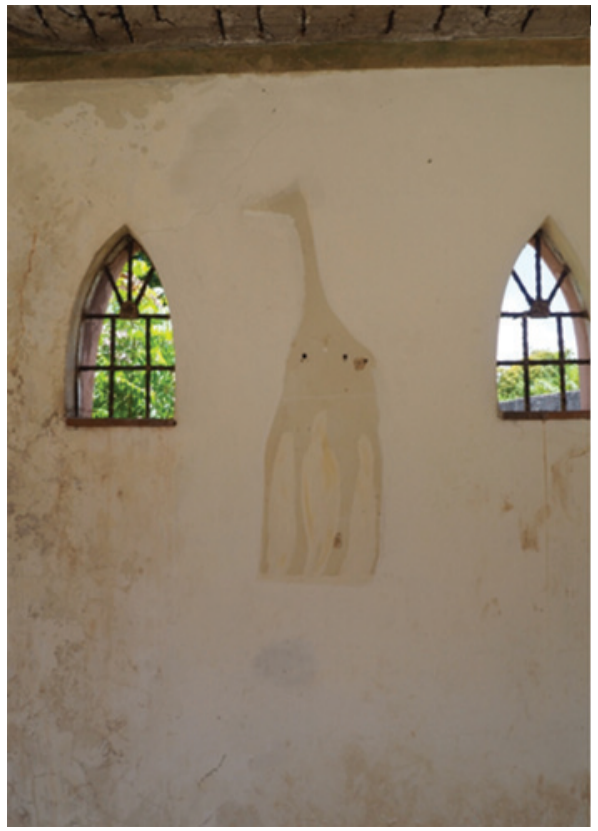

Figure 6.1 A vague giraffe

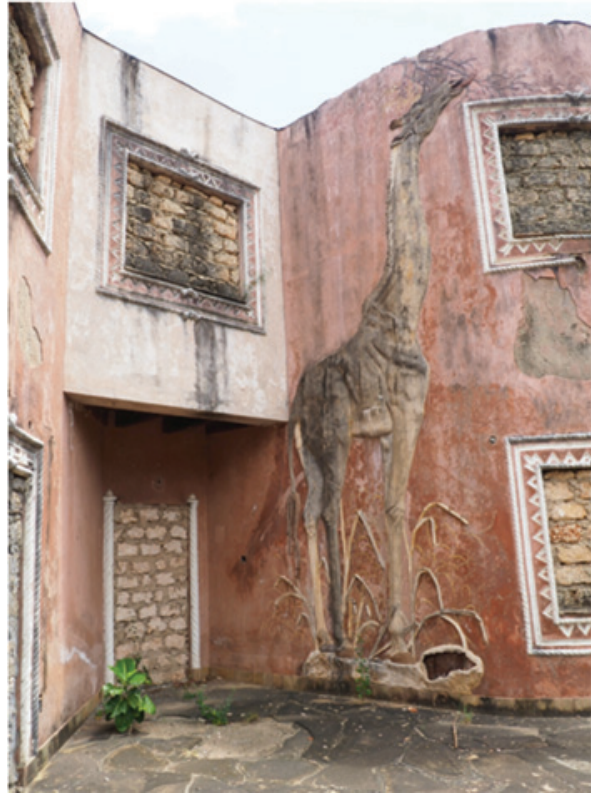

Figure 6.2 Giraffe and tree 


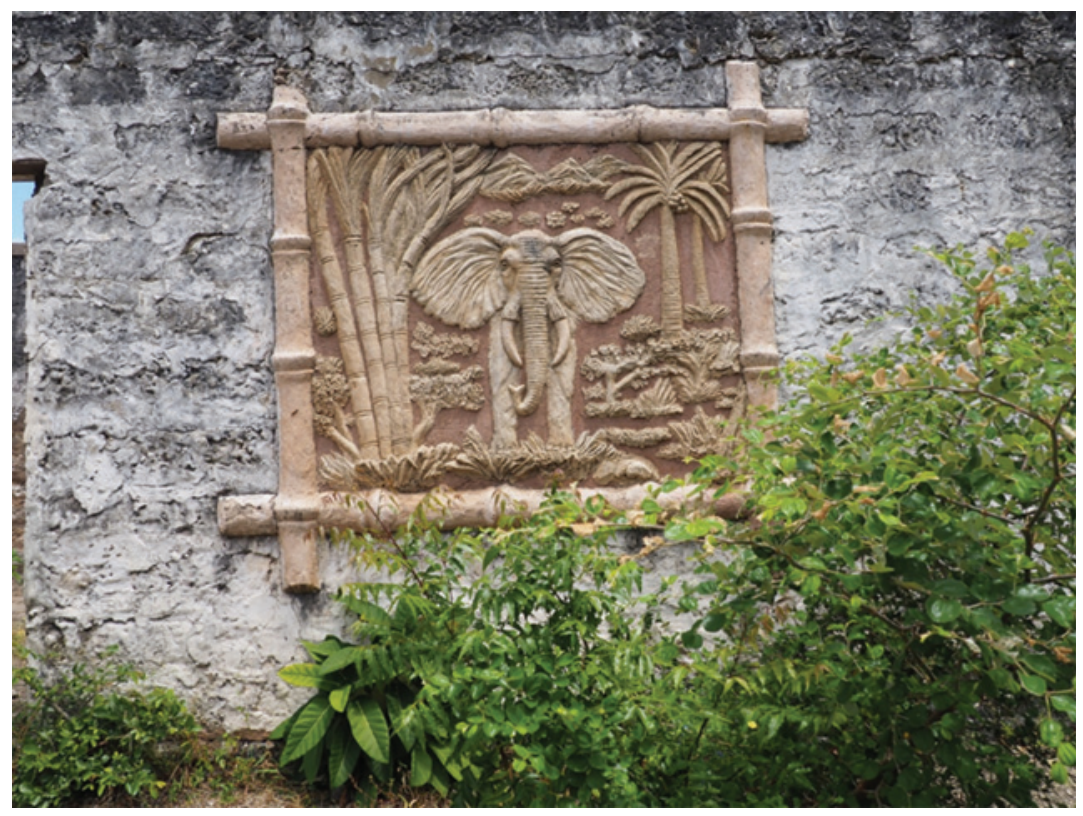

Figure 6.3 Elephant, trees and palms

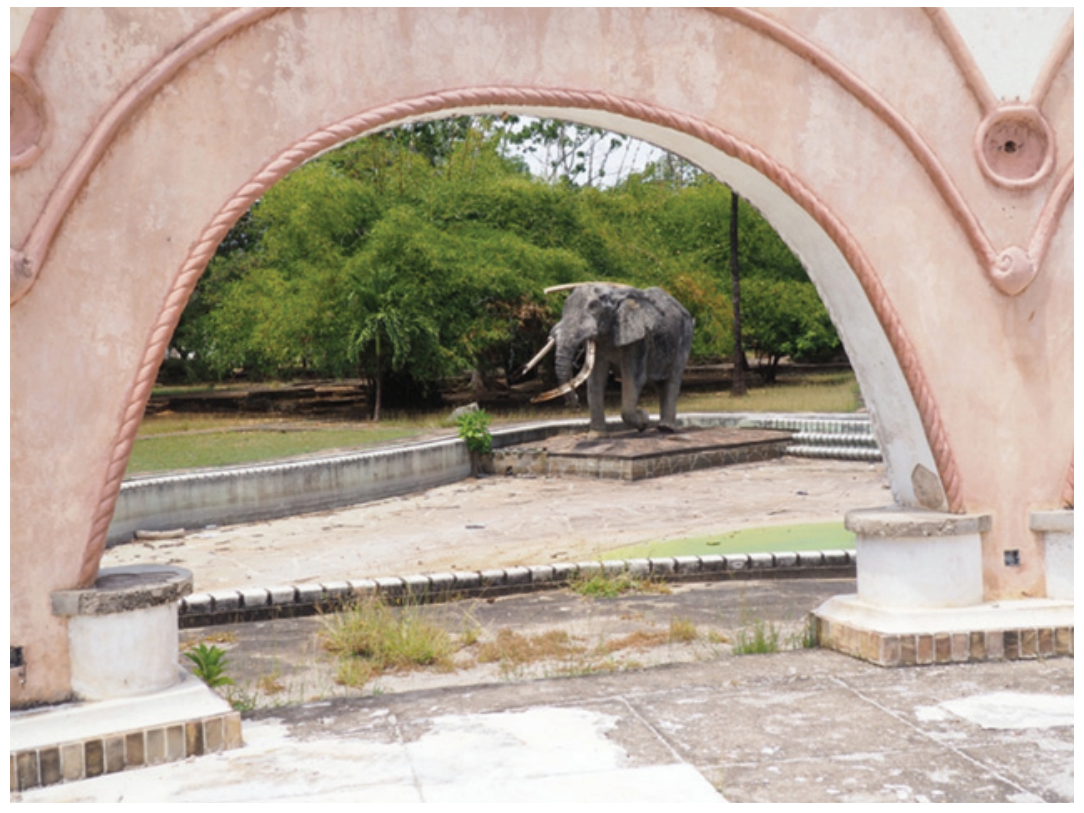

Figure 6.4 Elephant and pool (dry) 


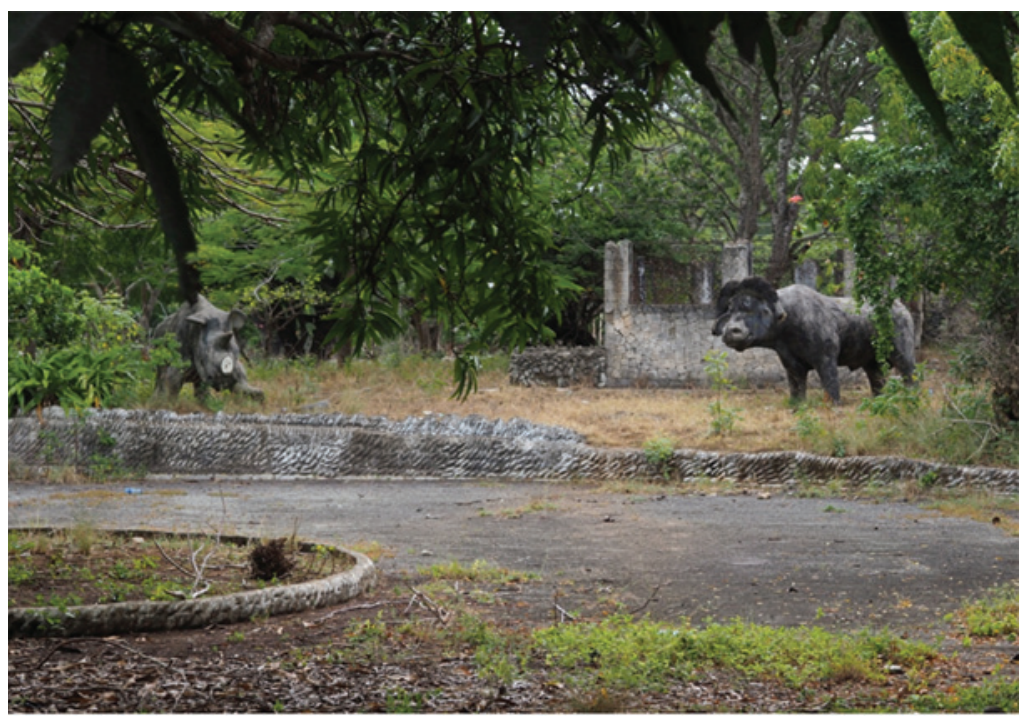

Figure 6.5 Buffalo and rhino amidst scenery

bush, they are shades and spectres that can be glimpsed at dusk. Vague sensations of other life that is also there, besides us. And as plants and cobwebs and other forms of life take over and transform the hellish nonplace of this tourism paradise into ruined space, the animals slowly come to life, are inhabited by other animals like birds and centipedes.

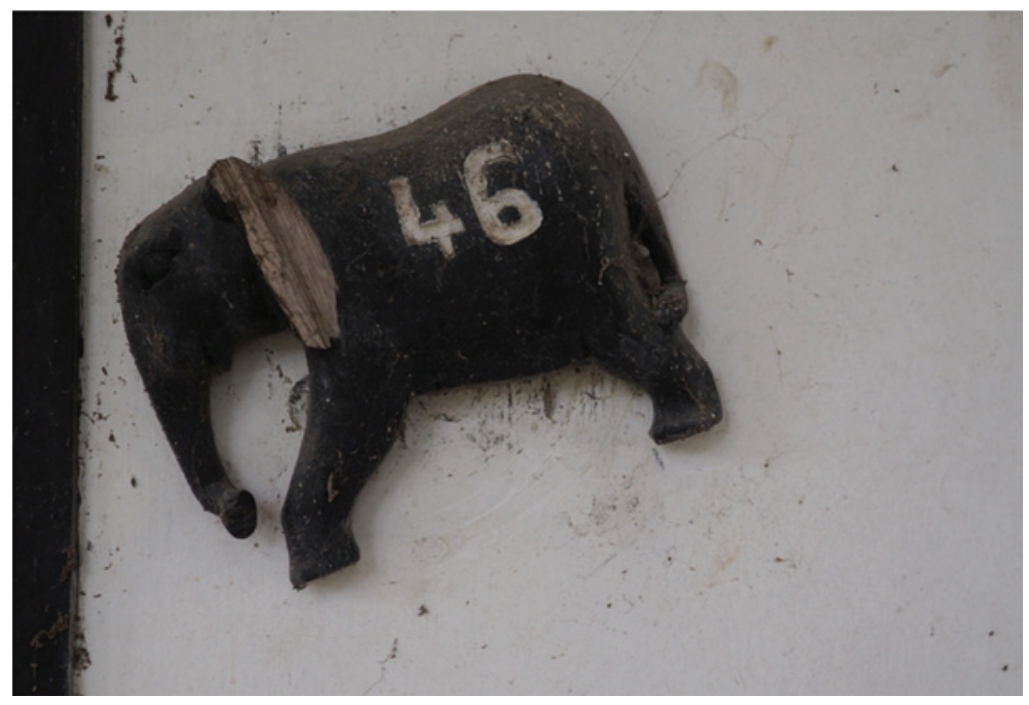

Figure 6.6 Numbered elephant 
A long time before this all happened, and before the roads were made wider and better and tourist complexes were built all along the coast, on littoral space, the area was covered with forest. What remains, as protected areas under UNESCO patronage, are sacred sites such as Kaya Kinondo, sacred forests. Everywhere else along the road leading south from Diani to the Tanzanian border are hotels, resorts, ruins of hotels and resorts, houses, ruins of houses, farmland and ruins of farmland. Villages remain 'authentic' and 'rural' because the only industry that money was put into was the tourism industry. Young men who have grown up in these villages hang out amidst all the ruined space at the beach and look after small businesses, or simply try to sell themselves, as there is nothing else there that can be sold.

Turning the gaze to ruins and ruination allows us to grasp the durabilities of marginal placement of particular people, namely people who, lacking access to particular economic resources, are considered 'local'. The construction of local young men as jobless, failing and criminal can also be seen as the continuation of inequality as a consequence of previous injustice and violence, of various kinds. The ruinations of places and people are ongoing processes that elegantly have been framed by the anthropologist and historian Ann Laura Stoler as the durabilities that imperial formations produce. Stoler points out that there is a 'relationship between colonial past and colonial presents, [and the] residues that abide and are revitalized' (Stoler, 2013: 5). The products of ruination are therefore complex and diverse, and while the residues of empire have often been assumed to consist of utterly tangible remains, Stoler argues that there are also other ruins: 'If the insistence is on a set of brutal finite acts in the distant slave-trading past, the process of decay is ongoing, acts of the past blacken the senses, their effects without clear termination. These crimes have been named and indicted across the globe, but the eating away of less visible elements of soil and soul more often has not' (Stoler, 2013: 1). Imperial debris therefore consists not simply of neocolonial hotel buildings rotting away in the tropics, or of the creation of world heritage sites that are what remains of a more complete social life, but also of ruined lives, of 'persons who become "a human ruin", "leftover" in their unexceptional, patterned subjection' (Stoler, 2013: 23) to abandonment and exclusion. In other words, ruination, the production of imperial debris, can result in poisonous environments, such as the coral reefs and marine ecosystems off the beach that have been destroyed by sand dredging, exploitation and pollution, but also in neocolonial economies that exclude people from sustainable incomes, and in images of young people as risk factors to social balance and order. 'To ruin', Stoler says, needs to be framed as a very agentive verb, an action that is powerful and that can be controlled by particular agents. Its duration, however, is out of the control of individual actors, she suggests: race is imperial debris, as are resentment, dispossession, and violent environments created through the uneven reallocation of access to resources. 
The young men who hang out in the ruins that were once profitable all-inclusive resorts ask for a bit of attention: a greeting, a bit of a shared walk, time for a chat. Human ruins, maybe, depending on how the subjective definition may allow us to judge the life of the local tourism workers. The term is not applied to the characteristics of the people, but rather to the life they had to adjust to after the income from tourism drastically decreased after its breakdown.

The topic of ruins, strangely, calls for images rather than words. Images of what this might look like - castles over the sea, expectations that hail from encounters with romanticism and gothic novels. Even industrial ruins and other recently lost places appear to produce mainly images, not text. The bizarre aesthetics of transformation ask for very particular genres - the coffee table book, the exhibition catalogue, the blog. And while images elsewhere might have the power to reveal, here they conceal and leave us daydreaming of colonial expeditions, discoveries of hidden treasures, precious lost things underneath the rubble.

It is striking that disadvantaged 'ruined' people are missing in the Kenyan world of high-class romantic daydreams, although they play a vivid role and are definitely more noticed by tourists than the stone ruins. The visual representations of the Kenyan poor are reserved for the oversized posters of NGOs that fill European cities at Christmas time. There, they form part of the colonial mechanisms that endure as they help us to construct, belittle and advertise the rest of the world. It remains a matter of space to transport what is to be transported.

The images of ruined space that are produced betray its temporary form and the transitions that take place. These ruins are fixed and stable, on high-quality paper and in nicely edited formats. But how can we speak or write of them? What kind of story emerges from the ruin?

While the older conceptions of rootedness and autochthony seem intellectually bankrupt, the heady theories of creative metissage have run aground upon the rocks of contemporary reality. (Greenblatt, 2010: 1)

This is what Stephen Greenblatt (2010) has to say about the urgency to 'rethink fundamental assumptions about the fate of culture in an age of global mobility' (Greenblatt, 2010: 1-2). In Cultural Mobility, he reminds us of the 'restless process through which texts, images, artefacts, and ideas are moved, disguised, translated, transformed, adapted, and reimagined in the ceaseless, resourceful work of culture' (Greenblatt, 2010: 4), which 'obviously long preceded the internet [...] or the spread of English on the wings of international capitalism. [...] The apparent fixity and stability of cultures is, in Montaigne's words, "nothing but a more languid motion"' (Greenblatt, 2010: 5).

What about language? At the remaining resorts, frozen in languid motion, guests lounge around pool areas, in restaurants and on balconies and stare at smartphones. They type a few words that form part of an 
Instagram story. Shoo away the waiter. More consumption: messages on the weather and the 'locals', on beaches and barbecues and home.

The smartphone has been seen as an agentive instrument to speed up both ruination and motion, through an incredibly fast distribution of images, ideas and language. Its materiality transcends class boundaries, as the tourists in the resort type their time away, as do those who wait for them outside the resort's boundaries, in taxis and tuktuks, at the beach and on the road. As a portable portal to the internet, the smartphone is increasingly thought to enable marginalized people to play central roles in contributing to social good across the globe and in enhancing change, as in the case of the activist and Iranian refugee Behrouz Boochani, who received the prestigious Victorian Premier's Literary Award in 2019 for his novel No Friend but the Mountains, which he wrote during his incarceration on Manus (where he remained for more than six years) with the help of a smartphone, as a series of seemingly endless WhatsApp messages. ${ }^{1}$ The smartphone obviously does more than merely linking migrants and places, enabling underprivileged people to obtain information, create networks and access foreign language (e.g. Beck \& Beck-Gernsheim, 2014; Bloch \& Donà, 2018; Deumert, 2014; Leurs, 2017; Lourente, 2017); it turns into a powerful instrument for changing the precise context out of which its necessity emerges, as a tool for southern critique on northern imperialism (Boochani, 2018: 20).

Yet this picture bears a strange similarity to earlier images of the colonial Other as an agent of humanism. It is not surprising that many of the published statements lauding Boochani's work highlight the role of his translator, to whom he sends his texts and who translates them from Kurdish into English and from WhatsApp into literature. But what happens to cultural products that travel through time and space to emerge and to be enshrined in new contexts and configurations?

\section{Old Roads}

Elsewhere, on the Mediterranean island of Mallorca, ruination has turned into performance and the smartphone into an amplifier. The beaches close to the island's airport are popular with party tourists, who mostly come from Germany and Britain, often only for a couple of days, in order to engage in the transgressive amusements of carnivalesque spaces. For some time now, the streets in front of the clubs and the beaches nearby have also attracted migrants from West Africa, who mostly come from Senegal and Nigeria, often for a couple of years, in order to participate in the petty economies surrounding the party space. As street vendors of cheap souvenirs, they are integrated by their customers into a performance of inversion and possession. German party tourists, who often wear colourful costumes such as party hats and motto T-shirts and mimetically perform clichéd lower-class practices, claim the island as a German colony, audibly in party songs and visually through text on 
bodies and buildings. The West African street vendors, similarly dressed in a carnivalesque manner, turn into a southern alter ego in this play, and into theatre props. They are uniformly addressed as Helmut, which is a common although old-fashioned name in Germany, and their images are circulated in this stereotyped representation through various Instagram and Facebook outlets (Nassenstein \& Storch, in press). Mocking the Other's Otherness is a play, everybody claims, which is, of course, organized according to the desires of the paying customers. This is without doubt obscene and transgressive, a performance of racist stereotypes and colonially based power. And in addition, the drunken tourists celebrate themselves with photos of their drunken companions.

Yet most of the Senegalese and Nigerian migrants prefer to convey different images, as the Nigerian-Spanish activist and entrepreneur Festus Badaseraye observes: 'Europe is paradise to most Africans. Europe has a better system than Africa. We don't have a social security system, look at our schools, roads, hospitals. Everything is better here in Europe' (personal communication, March 2019). The experiences of exclusion, abuse, exploitation and lack of success are hardly ever communicated to others, and likewise most migrants keep silent about bouts of depression and angst (Lindtner, 2018; Smith, 2019). There is a sense of shame, M., a man in his mid-thirties said, in being forced to live in such a situation, while people back home, who have invested so much, expect success stories. A., who has lived as an undocumented migrant almost exclusively in the party zone, where he feels safe from the police, says that he prefers to send home images of clean, quiet places on WhatsApp, the opposite of the noisy working contexts in which he usually operates.

Among the migrants themselves, however, different material is circulated. While waiting for customers, one cannot help watching what happens: the decadence of intoxicated tourists who seem to have too much to spend, heterosexual White males in a heteronormative White male space, where women are gang-banged in the cheap triple rooms of the Hotel Niagara, or where one can afford a cheap blow job by one of the women working in the streets nearby, where migrants are integrated into the party space as complicit persons who can be molested and abused in a drunken performance of superiority. And one can make short films of what one sees, because the superiority is such that the superior appears not to be afraid of the defacement. The little videos that are circulated, among those who might have come there expecting other sights than these, are videos about temporary but crucial losses of control.

The first video was of a young man in swimming trunks who jumped from a hotel balcony into the pool, narrowly missed it and broke his hips on the concrete. Balconing has claimed several deaths among intoxicated tourists in the past few years. An anti-tourism graffiti in Barcelona reads balconing is fun.

The second video we see shows 12 seconds in the life of an obese young man who wears an orange party wig and matching Borat swimsuit, 
sunglasses, purse and black sneakers. He walks down an average road (not a party boulevard). One hears men who are softly laughing.

Then a film made at night. A young man has vomited in front of a grocery shop, just in front of some waiting taxis. He went into the shop, bought a toothbrush and toothpaste and cleaned his teeth, standing on the sidewalk. Other men try discreetly to push him aside, away from the shop. He moves only a little, then throws toothbrush and paste on the street, spits and moves on. Laughter, expressions of surprise and disbelief.

The next video shows a street at night and lasts 31 seconds. A man stands on a sidewalk and masturbates into the mouth of a woman who kneels in front of him. A voice repeats, in disbelief, Esto lo que pasa en El Arenal. Que grande. Most of the spoken comments on these videos are in Spanish (never Mallorquin), which is used in leisurely situations among many long-term migrants from West Africa. And then, 'very sorry [...] this happened in Arenal' is written in the text message underneath. In the party zone, there are signs indicating high fines for public sex.

And so on.

Nobody understands this drunkenness, we are told. Yet these films are comparably peculiar, particular and local to what is circulated by the tourists, whose posts we see as mimetic practices, playing with Othering. We suppose that these West African videos are more complex than this. In an environment where one is largely negated as a coeval person, is denied the rights of hospitality and citizenship, discourse is more fundamentally annihilated. Conversation is replaced by declaration, addressing by naming. Mimesis runs aground.

A., a Nigerian lavatory attendant in one of the clubs, reports that many of her clients are excessively drunk when they use the toilet and often need to be washed and helped. She supplies the women with deodorant sprayed under the arms and between their legs and with anything from chewing gum to make-up to 'civilize them again', as she says. She regains control over her working environment and earns some tips as added value. She and her colleagues find the tourists lacking in education, an opinion shared by many of the street vendors outside. The migrants in the party space claim the task of providing this, as Behrouz Boochani claims that he and other refugees return humanity to Australia.

The images, therefore, are the symbolic proof of a denial of hospitality that creates failed hosts, turning them into obscene people and pitiful sights. Obscene visual material here obtains the status of a magical object, turning the artificiality of the smartphone and the signs it produces into a powerful instrument that is able to make meaning of one's place in the world. The philosopher Souleymane Bachir Diagne has made this a bit more transparent in his (2013) dialogue on truth and untruth. Bachir Diagne is interested in the cultural mobility of ideas and in how pre-existing or local thought is integrated into Islamic religious practice in Wolof society. The deeper meaning in the folktales about experiences of the 
appropriation of the local into the global, he suggests, is that they tell us that 'belief leads to truth, although what we usually think is that truth leads to belief' (Bachir Diagne, 2013: 5). Inhospitality and accusations of sorcery - practices directed against the abject Other - are practices that oppose the norms and values of religion and relate to local practices and local systems of belief, he suggests. In this constellation,

truth is the path that exists, the untruth is what deviates from the path which is delineated. [...] So the truth is not only what is. It is also what should be. Consequently, when someone does something wrong, he is told that what he did is not the truth, it deviates from the path. (Bachir Diagne, 2013: 11)

In a non-discursive setting, where there is no place for such a conversation, the digitally circulated obscenity turns into magic that serves as a protection from precarity and debasement. And because religious truth does not nullify the local - tradition, as Bachir Diagne writes - it needs to replace it as well as to renew it. Civilization workers are now able to do their task:

Former President Senghor often used to say that the people's tradition is not something that [religion] should displace: it should melt into it, penetrate its essence. [...] Then we can come to an agreement that tradition is not enough for us to talk about truth, we should say making sense and agreeing with the times. (Bachir Diagne, 2013: 13)

Whatever is undesirable that the local, the traditional, holds in store, there is the endless potential of culture - religion - to transform itself and that with which it is confronted. The abyss of the internet, the ubiquity of social media, are not given much meaning here. What counts is transformation, it seems, which is based on time. 'Not language, only process', a Nigerian woman, who talked about her migration into all this, told us.

We end this with two suggestions of how to come to a deeper understanding of the transformative power of that which is shown and that which is not shown. We end with two different thinkers, a Senegalese philosopher and a British historian, who come to the same conclusion:

Mobility studies [...] are essentially about what medieval theologians called contingentia, the sense that the world as we know it is not necessary: the point is not only that the world will pass away, but also that it could all have been otherwise. This contingentia is precisely the opposite of the theory of divinely or historically ordained destiny that drove the imperial and figural models of mobility. [...] How is it possible to convey a sense of contingentia (and its counterbalancing illusion of fixity) in practice? [...] Montaigne's response was not to try to construct an abstract system but to try to describe a single object in motion, himself. (Greenblatt, 2010: 16f.)

I will stop our conversation here then. There may be some other thoughts that occurred to me during the conversation, such as the meaning of 'time' ... We will just have to leave it at that for the time being, as it is getting late. [...] [L]et us go our way. (Bachir Diagne, 2013: 13) 
From here on, there remain images of what can be shown of a walk from the beach back to the airport, from where tourists return home and migrants are deported to what might not be a home any longer (Figures 6.7-6.12).

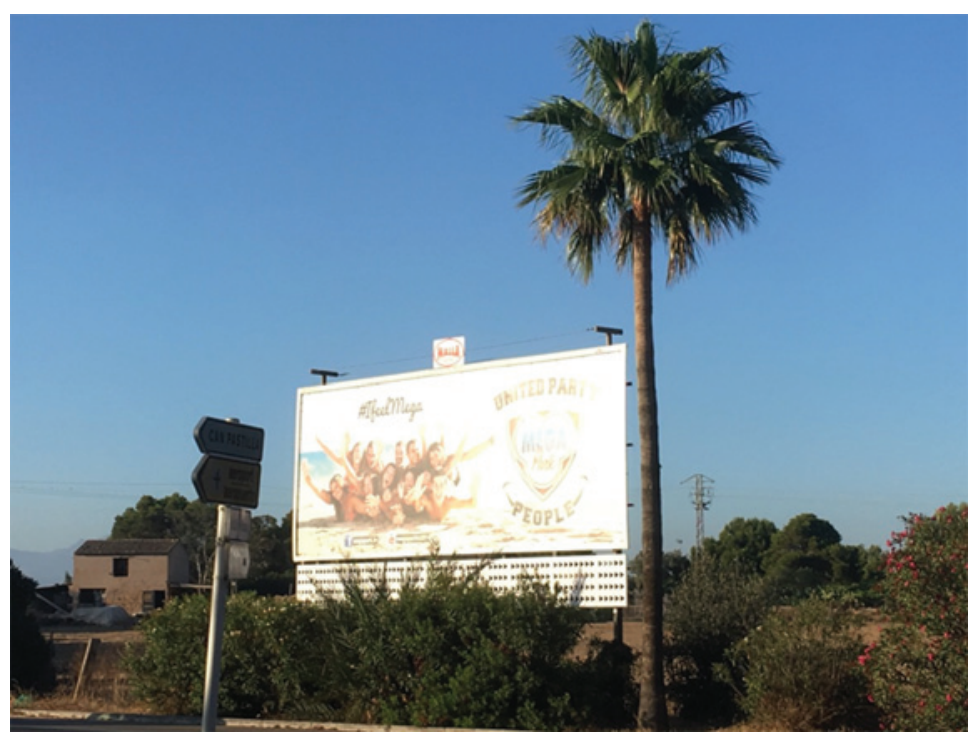

Figure 6.7 Ad and palm tree

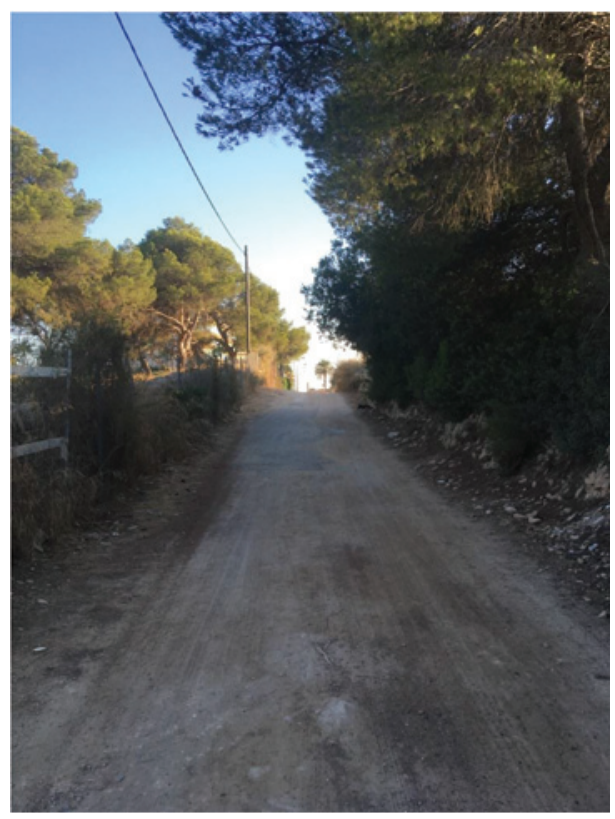

Figure 6.8 Road and pine trees 


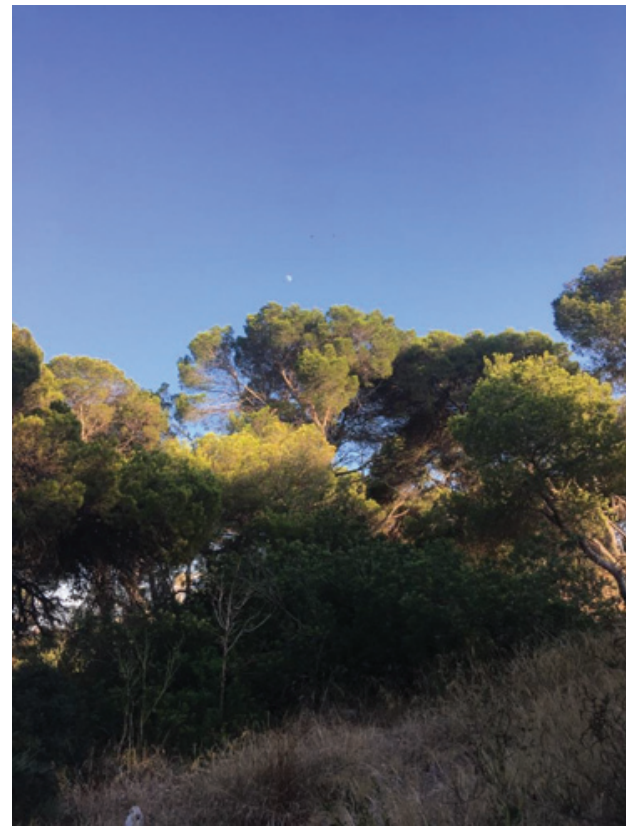

Figure 6.9 More pine trees

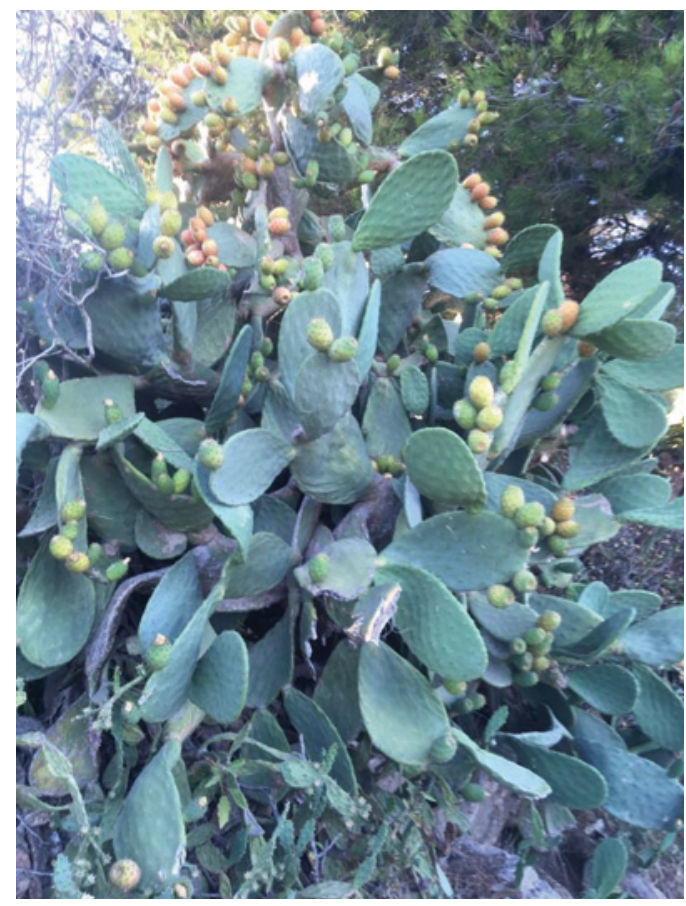

Figure 6.10 Pine trees and cactus 


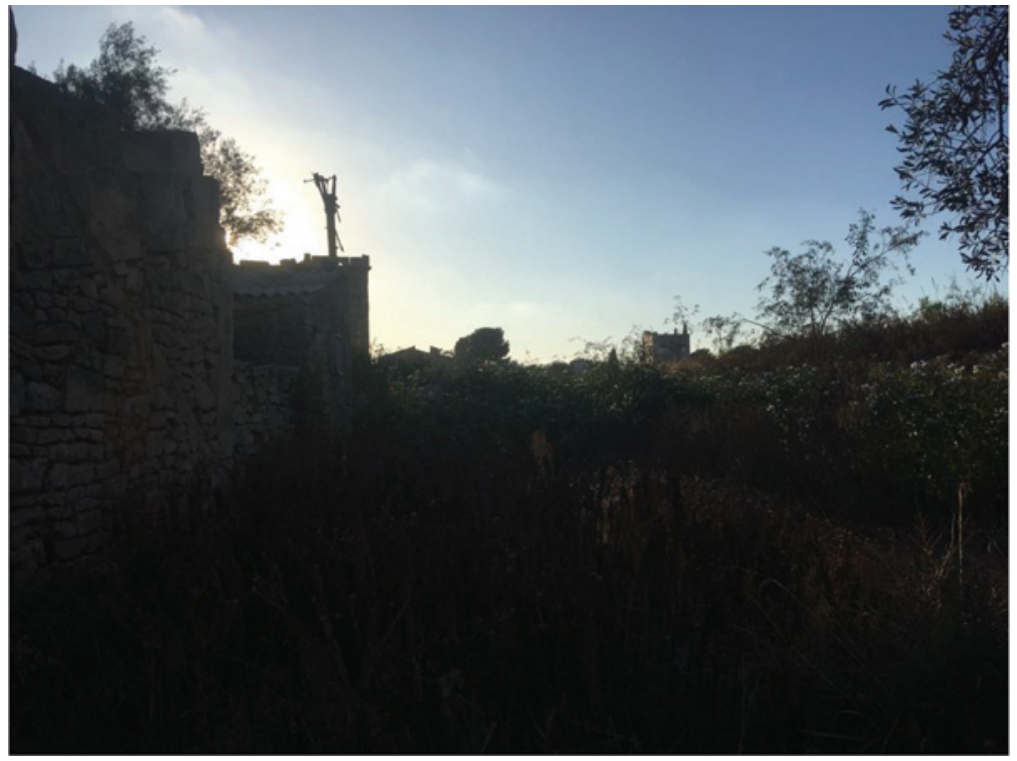

Figure 6.11 Windmill ruins

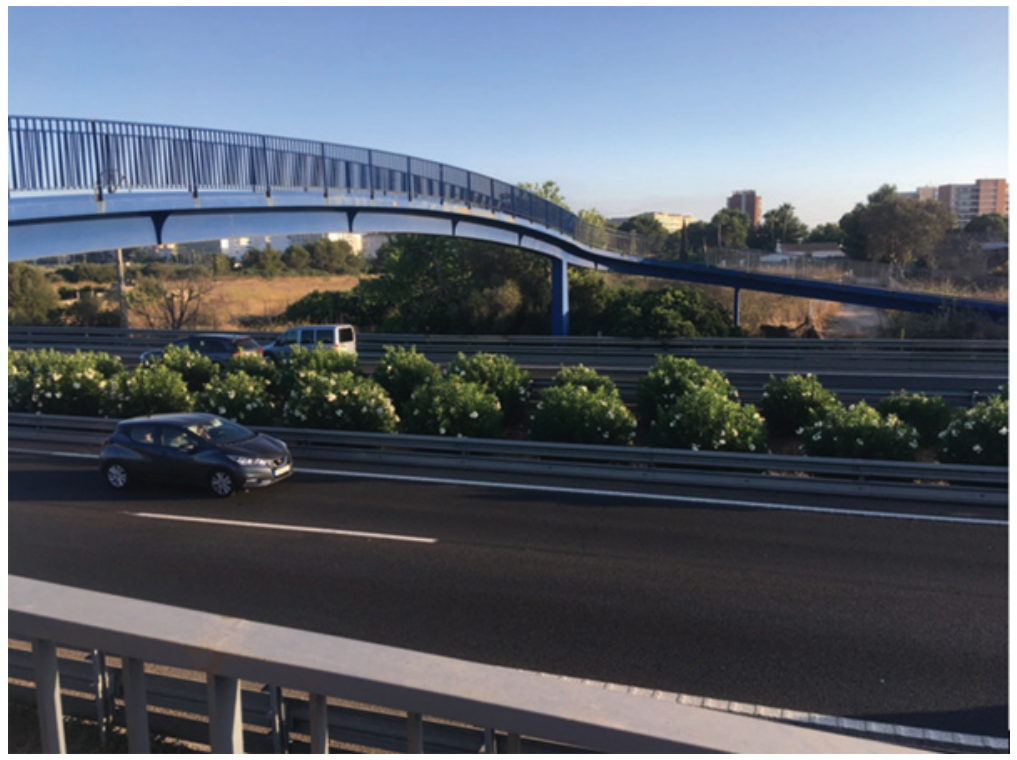

Figure 6.12 Highway bridge

\section{Note}

(1) See https://www.bbc.com/news/world-australia-47072023 (accessed 12 August 2020). 


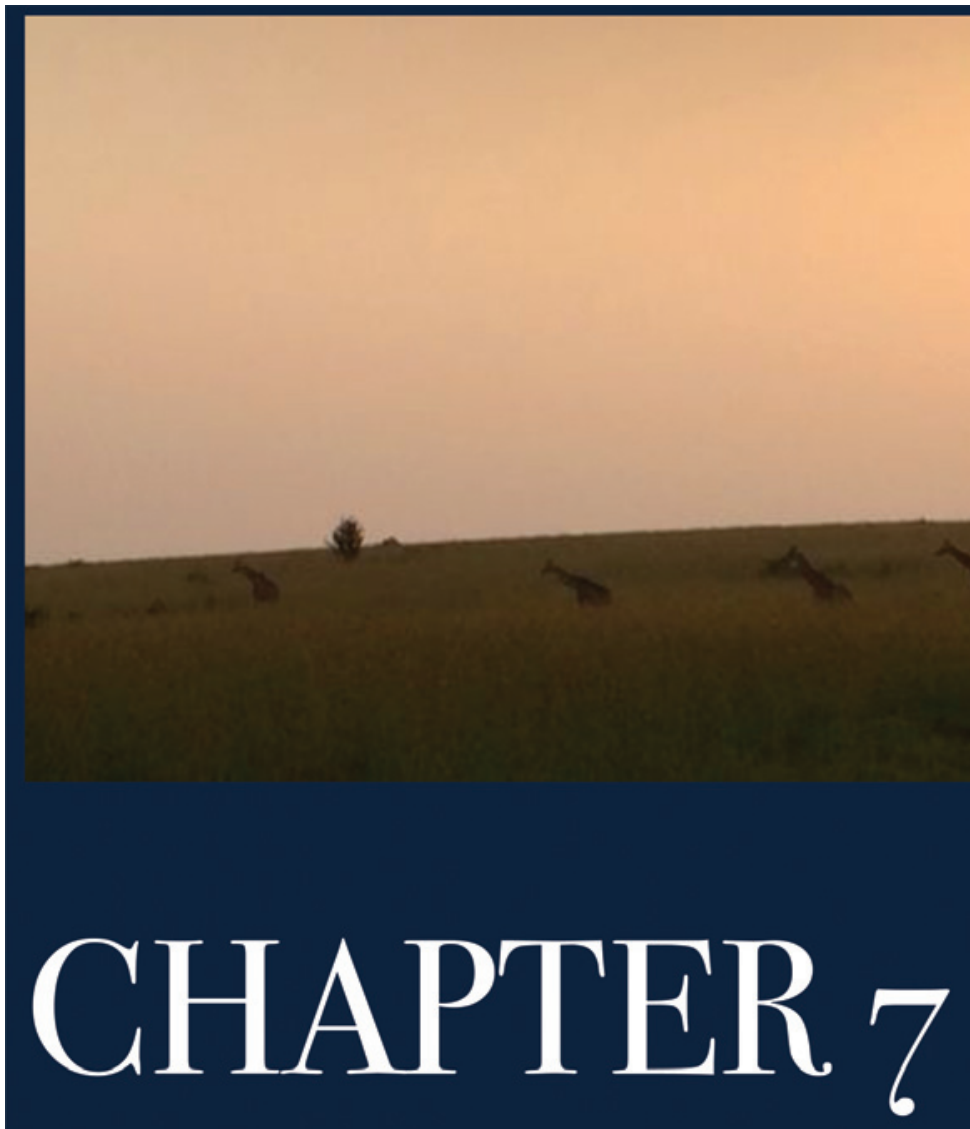

RELOCATION AND RELATIONSHiPS

Explore the explored

know the known

Name the named Eat the cooked Spurn the raw 